DOI: 10.2478/romneu-2014-0014

\title{
Risk Factors for Re-bleeding of Aneurysmal Subarachnoid Hemorrhage: Systemic Review and Meta Analysis
}

\author{
Alfotih Gobran Taha, Fang Cheng Li, Xin Ke Xu, Shang Yi Zhang \\ Sun Yat Sen Memorial Hospital, Neurosurgery Department, Sun Yat Sen Medical University, \\ Guang Zhou, Guang Dong Province, People's Republic of China
}

\begin{abstract}
Objective: The mortality of re-bleeding is high and patients surviving are usually in poor clinical condition and have a worse outcome than patients with single bleed. We performed an update systemic review and Meta-analysis to determine the most common risk factors for re-bleeding in aneurysmal subarachnoid hemorrhage patients.
\end{abstract}

Method: We reviewed all publications on the risk factors of the re-bleeding or rerupture of already bled intracranial aneurysms. This Meta analysis included studies published from the year 2000 until 2013. Pooled mean difference was calculated for the continuous variables (Age), and pooled odds ratio (OR) was calculated for categorical factors. Heterogeneity was tested first. If it is significant $(\mathrm{p}<0.05)$, random effect model was applied, otherwise, fixed model was used. Software - Review manager was used to find pooled effects and perform significant test for each potential risk factor.
Results: We identified 174 articles. Only 7 retrospective studies had met the inclusion criteria, with 2470 patients, 283 patients had aneurysmal re-bleeding. The weighted average rate of re-bleeding is $11.3 \%$ with $95 \%$ confidence interval [CI]: 10.1-12.6. Statistically significant risk factor for re-bleeding were sex (OR 1.46; 95\% CI: $1.11,1.92)$, high systolic blood pressure [SBP] (OR 2.52; 95\% CI: 1.40, 4.53), aneurysm size (OR 3.00; 95\% CI: 2.06$4.37)$, clinical condition (Hunt \& Hess) (OR 4.94; 95\% CI: 2.29, 10.68), and Fisher Grade (OR 2.29; 95\% CI: 1.45, 3.61).

Conclusion: Sex, high SBP, high Fisher Grade, aneurysm size larger than $10 \mathrm{~mm}$, and patients with poor clinical condition (Hunt \& Hess) were independent risk factors for aneurysmal re-bleeding. The importance of early aneurysm intervention should be emphasized to eliminate the risk of re-bleeding and poor outcome.

Key words: Cerebral aneurysm, Subarachnoid hemorrhage, re-bleeding, risk factor, Meta-Analysis. 


\section{Introduction}

$10-15 \%$ of patients with aneurysmal SAH die before reaching medical care [1]. A further $5 \%$ die within the first 24 hours of SAH. By the 30th day of SAH, the overall case fatality rate increases to nearly $50 \%$ [1] [2]. Of the survivors $25-30 \%$ of patients re-bleed within the first four weeks from the SAH. After the first six weeks of $\mathrm{SAH}$, the re-bleeding rate is about $4 \%$ per year. $50 \sim 90 \%$ of re-bleeding episodes occur in the first 6 hours after the primary bleed [3] [4]. Mortality is reported to be as high as $75 \% \sim 80 \%$ in patients who re-bled from their aneurysm [5] [6] [7] [8]. The rate of re-bleeding will be high if the aneurysm left untreated. $25 \%$ die as a result of medical complications of $\mathrm{SAH}$ [9], like neurogenic pulmonary edema and neurogenic stunned myocardium. For these reasons, early detection and accurate evaluating the incidence of re-bleeding, predictors for re-bleeding is mandatory. Factors associated with aneurysm rebleeding are still controversial. Re-bleeding can occur before the patients are admitted or during transfer to the hospital [10] [11]or after hospitalization.

In this study we included parameters that were available after admission. We had reviewed 9 factors that may have significant impact on re-rupture after primary bleeding. These findings could give neurologists, neurosurgeons, and health care providers with most common risk factors for re-bleeding in subarachnoid hemorrhage patients.

\section{Method}

We reviewed all publications on the risk of the re-bleeding or re-rupture of already bled intracranial aneurysms. This Meta analysis included studies published from the year 2000 until 2013. We performed a MEDLINE, EMBASE, COCHRANE, Web of Science search. The following keywords were used in different combination: Cerebral aneurysms, Intracranial aneurysms, re-bleeding, re-rupture, recurrent hemorrhage, risk factors. We searched the reference lists for all relevant publications for additional studies, and the references of the publications thus found were checked again.

\section{Inclusion criteria:}

1- Patients with SAH due to aneurysmal re-rupture after previous bleeding, proved by imaging studies such as magnetic resonance image (MRI), computed tomography angiography (CTA), digital subtraction angiography (DSA). 2- studies comparing multi risk factors in re-bleeding and non re-bleeding groups such as: Sex, age, clinical conditions at admission (Hunt \& Hess), hypertension, location of aneurysm, multiple aneurysms, size of aneurysm, Fisher Grade, external ventricle drainage (EVD).

\section{Exclusion criteria:}

1- fewer than 20 patients were included, because smaller studies are more likely to suffer from selection bias. 2- multiple reports were published for the same study population. 3-the article was a review, a case report, or editorial. 4- SAH due to 
DOI: 10.2478/romneu-2014-0014

non aneurysmal pathology (trauma, AVM, etc.). 5-non English language articles.

\section{Data extraction:}

Two reviewers independently extracted data from the studies that met the inclusion criteria. Information was extracted on patient, aneurysm characteristics, pre-operative treatment. In case of disagreement between the 2 reviewers, consensus was reached by joint review.

The location of the aneurysms was classified as follows (1): anterior circulation: anterior communicating artery, internal carotid artery, anterior cerebral artery, middle cerebral artery, posterior communicating artery. (2) posterior circulation: vertebral artery, basilar artery, posterior cerebral artery.

Because in the studies different cut points were used for aneurysm size, we made the following categories: $\geq 10 \mathrm{~mm}$ and $<10 \mathrm{~mm}$. Others factors were classified as follow: Hunt \& Hess: IV-V and I-II-III, Fisher Grade: $\geq 3$ and $<3$.

\section{Measurements index:}

Age, sex, hypertension, aneurysm location, multiple aneurysms, size, Hunt \& Hess, Fisher Grade and external ventricle drainage.

\section{Data analysis:}

1. Data (9 factors) were extracted from the 7 papers and entered into excel sheet.

2. Software - Review manager was used to find pooled effects and perform significant test for each potential risk factor.

3. Pooled mean difference was calculated for the continuous variables (Age), and pooled odds ratio was calculated for categorical factors.

4. Heterogeneity was tested first. If it is significant $(\mathrm{p}<0.05)$, random effect model was applied, otherwise, fixed model was used.

\section{Results}

We identified 174 articles. Only7 retrospective studies had met the inclusion criteria, with 2470 patients, 283 patients had aneurysmal re-bleeding (Table 1). And we made a quality evaluation to every research by use of the Newcastle-Ottawa Scale (NOS). Results of quality evaluation shown most of seven researches had high quality (Table 2). The weighted average rate of re-bleeding is $11.3 \%$ with $95 \%$ confidence interval: 10.112.6.

Meta-analysis result

Sex (OR 1.46; 95\% confidence interval [CI]: 1.11, 1.92), high systolic blood pressure [SBP] (OR 2.52; 95\% CI: 1.40, 4.53), aneurysm size (OR 3.00; 95\% CI: 2.06-4.37), clinical condition (Hunt \& Hess) (OR 4.94; 95\% CI: 2.29, 10.68), and Fisher Grade (OR 2.29; 95\% CI: 1.45, 3.61). Whereas age, aneurysm location, multiple aneurysms and external ventricular drainage (EVD) in this analysis are not significant risk factors for rebleeding in aneurysmal SAH patients (Table 3). 
TABEL 1

Overview of the 7 included studies

\begin{tabular}{|c|c|c|c|c|c|c|c|c|c|c|}
\hline \multirow[t]{2}{*}{ Author } & \multirow{2}{*}{$\begin{array}{l}\text { Publication } \\
\text { year }\end{array}$} & \multicolumn{3}{|c|}{ Patient No\# } & \multirow{2}{*}{$\begin{array}{l}\text { Rebleeding } \\
\text { rate }\end{array}$} & \multirow{2}{*}{$\begin{array}{l}\text { Study period } \\
\text { (year) }\end{array}$} & \multirow[t]{2}{*}{ design } & \multirow{2}{*}{$\begin{array}{l}\text { Diagnosis } \\
\text { Of rebleeding }\end{array}$} & \multirow[t]{2}{*}{ Journal } & \multirow{2}{*}{$\begin{array}{l}\text { Details of } \\
\text { patient } \\
\text { selection }\end{array}$} \\
\hline & & total & Rebleed & No-rebleed & & & & & & \\
\hline $\begin{array}{l}\text { KC Cha et } \\
\text { al. }\end{array}$ & 2010 & 492 & 38 & 454 & $8.4 \%$ & $\begin{array}{l}12 \\
(1995-2007)\end{array}$ & Retrospective & CT & $\begin{array}{l}\text { J. Korean } \\
\text { Neurosurg Soc }\end{array}$ & No \\
\hline Beck et al. & 2006 & 237 & 23 & 214 & $10.7 \%$ & $\begin{array}{l}3 \\
(1999-2002)\end{array}$ & Retrospective & CT & Stroke & No \\
\hline $\begin{array}{l}\text { Lie Mei } \\
\text { Guo et al. }\end{array}$ & 2013 & 326 & 70 & 256 & $27.3 \%$ & $\begin{array}{l}9.3 \\
(2002-2010)\end{array}$ & Retrospective & $\begin{array}{l}\text { CT or lumbar } \\
\text { puncture }\end{array}$ & $\begin{array}{l}\text { World } \\
\text { Neurosurg }\end{array}$ & No \\
\hline $\begin{array}{l}\text { Cong W. } \\
\text { et al. }\end{array}$ & 2012 & 458 & 63 & 395 & $15.9 \%$ & $\begin{array}{l}3 \\
(2005-2008)\end{array}$ & Retrospective & CT & $\begin{array}{l}\text { Turkish } \\
\text { Neurosurgery }\end{array}$ & Yes \\
\hline $\begin{array}{l}\text { Naidech et } \\
\text { al. }\end{array}$ & 2005 & 574 & 40 & 534 & $7.5 \%$ & $\begin{array}{l}6 \\
(1996-2002)\end{array}$ & Retrospective & CT & Arch Neurol & Yes \\
\hline $\begin{array}{l}\text { Ohkuma } \\
\text { Et al. }\end{array}$ & 2001 & 273 & 37 & 236 & $15.7 \%$ & $\begin{array}{l}10 \\
(1989-1998)\end{array}$ & Retrospective & CT & Stroke & Yes \\
\hline $\begin{array}{l}\text { Wu TC. et } \\
\text { al. }\end{array}$ & 2012 & 110 & 12 & 98 & $12.2 \%$ & $\begin{array}{l}3 \\
(2007-2010)\end{array}$ & Retrospective & CT & $\begin{array}{l}\text { J. comput assist } \\
\text { Tomogr }\end{array}$ & Yes \\
\hline Total & & 2470 & 283 & & & & & & & \\
\hline
\end{tabular}

TABEL 2

The risk factors of the studies and quality evaluation in the meta-analysis

\begin{tabular}{|l|l|c|}
\hline Authors & Risk Factor & Scores \\
\hline KC Cha et al. & A B C D E F G H & 7 \\
\hline Beck et al. & A B F H I & 8 \\
\hline Lie Mei Guo et al. & A B C D F G H & 8 \\
\hline Cong W. et al. & A B C D E G & 8 \\
\hline Naidech et al. & G I & 8 \\
\hline Ohkuma et al. & A B C D G & 7 \\
\hline Wu TC. et al. & A B C D F H & 7 \\
\hline
\end{tabular}

TABEL 3

Meta - analysis

\begin{tabular}{|c|c|c|c|c|c|c|c|c|}
\hline \multirow[t]{2}{*}{ Factor } & \multirow[t]{2}{*}{$\begin{array}{l}\text { Number } \\
\text { of studies }\end{array}$} & \multicolumn{2}{|c|}{$\begin{array}{l}\text { Heterogeneity } \\
\text { chi-squared }\end{array}$} & \multirow[t]{2}{*}{$\begin{array}{l}\text { Models of } \\
\text { meta-analysis }\end{array}$} & \multirow[t]{2}{*}{$\begin{array}{l}\text { Pooled } \\
\text { OR }\end{array}$} & \multirow[t]{2}{*}{$95 \% \mathrm{CI}$} & \multirow[t]{2}{*}{$\mathrm{Z}$} & \multirow[t]{2}{*}{$\mathrm{P}$} \\
\hline & & $\mathrm{P}$ & $\mathrm{I}^{2}(\%)$ & & & & & \\
\hline Age (mean) & 6 & 0.009 & 67 & Random & 1.72 & $-1.61-5.04$ & 1.01 & 0.31 \\
\hline $\begin{array}{l}\text { Sex } \\
\text { Male vs. female }\end{array}$ & 6 & 0.61 & 0 & Fixed & 1.46 & $1.11-1.92$ & 2.71 & 0.007 \\
\hline Hypertension & 4 & 0.01 & 72 & Random & 2.52 & $1.40-4.53$ & 3.08 & 0.002 \\
\hline
\end{tabular}


DOI: 10.2478/romneu-2014-0014

\begin{tabular}{|c|c|c|c|c|c|c|c|c|}
\hline $\begin{array}{l}\text { Location } \\
\text { Anterior circulation vs. } \\
\text { posterior circulation }\end{array}$ & 5 & 0.83 & 0 & Random & 1.59 & $0.72-3.48$ & 1.15 & 0.25 \\
\hline Multiple aneurysms & 2 & 0.12 & 58 & Fixed & 1.11 & $0.58-2.09$ & 0.31 & 0.76 \\
\hline $\begin{array}{l}\text { Size } \\
\geq 10 \mathrm{~mm} \text { vs. }<10 \mathrm{~mm} .\end{array}$ & 4 & 0.11 & 50 & Fixed & 3.00 & $2.06-4.37$ & 5.74 & 0.00001 \\
\hline $\begin{array}{l}\text { Hunt-Hess grade } \\
\text { IV-V vs. I-II-III }\end{array}$ & 5 & 0.0001 & 83 & Random & 4.94 & $2.29-10.68$ & 4.07 & $<0.0001$ \\
\hline $\begin{array}{l}\text { Fisher grade } \\
\geq_{3 \text { vs. }<3}<3\end{array}$ & 4 & 0.34 & 11 & Fixed & 2.29 & $1.45-3.61$ & 3.55 & 0.0004 \\
\hline $\begin{array}{l}\text { External ventricular } \\
\text { drainage (EVD) }\end{array}$ & 2 & 0.03 & 78 & Random & 2.96 & $0.86-10.22$ & 1.72 & 0.09 \\
\hline
\end{tabular}

Meta-analysis result

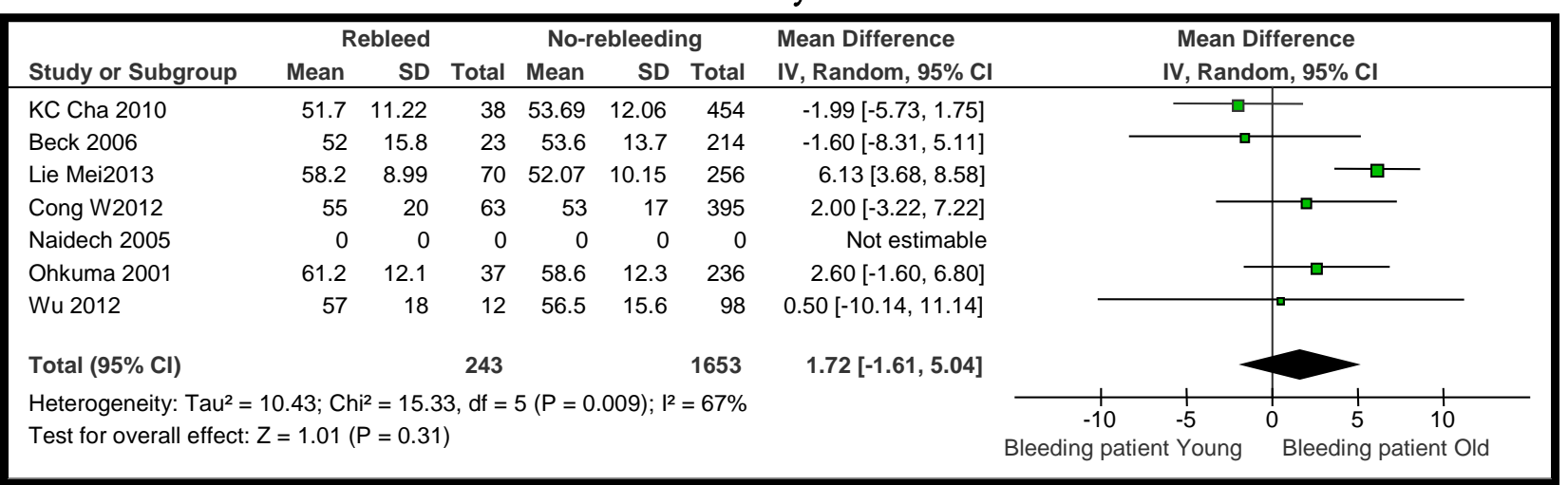

\section{Re-bleeding and age:}

There are 6 studies describing age and re-bleeding. Pooled effects: OR (95\% CI): $1.72(-1.61,5.04)$, P-values for pooled effect: $0.31, \mathrm{P}>0.05$, there is no statistical difference between the subgroups.

\begin{tabular}{|c|c|c|c|c|c|c|c|c|c|}
\hline \multirow{2}{*}{ Study or Subgroup } & \multicolumn{2}{|c|}{ Rebleeding } & \multicolumn{2}{|c|}{ No-rebleeding } & $\begin{array}{c}\text { Odds Ratio } \\
\text { M-H, Fixed, 95\% Cl }\end{array}$ & \multicolumn{3}{|c|}{$\begin{array}{c}\text { Odds Ratio } \\
\text { M-H, Fixed, 95\% Cl }\end{array}$} & \\
\hline & 21 & 38 & 161 & 454 & $2.25[1.15,4.38]$ & & & - & \\
\hline Beck 2006 & 11 & 23 & 87 & 214 & $1.34[0.56,3.17]$ & & & & \\
\hline Lie Mei2013 & 31 & 70 & 99 & 256 & $1.26[0.74,2.15]$ & & & & \\
\hline Cong W2012 & 32 & 63 & 147 & 395 & $1.74[1.02,2.97]$ & & & & \\
\hline Naidech 2005 & 0 & 0 & 0 & 0 & Not estimable & & & & \\
\hline Ohkuma 2001 & 17 & 37 & 73 & 163 & $1.05[0.51,2.15]$ & & & & \\
\hline Wu 2012 & 6 & 12 & 33 & 65 & $0.97[0.28,3.32]$ & & & & \\
\hline Total $(95 \% \mathrm{Cl})$ & & 243 & & 1547 & $1.46[1.11,1.92]$ & & & & \\
\hline \multirow{2}{*}{\multicolumn{5}{|c|}{$\begin{array}{l}\text { Total events } \quad 118 \quad 600 \\
\text { Heterogeneity: } \mathrm{Chi}^{2}=3.60, \mathrm{df}=5(P=0.61) ; \mathrm{I}^{2}=0 \% \\
\text { Test for overall effect: } Z=2.71(P=0.007)\end{array}$}} & & & & & \\
\hline & & & & & & 0.2 & $\begin{array}{c}0.5 \\
\text { Female }\end{array}$ & $1{ }^{2}$ & 5 \\
\hline
\end{tabular}

$$
\text { 2. Re-bleeding and sex: }
$$

There are 6 studies describing sex and re-bleeding. Pooled effects: OR (95\% CI): 1.46 (1.11, 1.92), P-values for pooled effect: $0.007, \mathrm{P}<0.05$, there is significant statistical difference between the subgroups. 


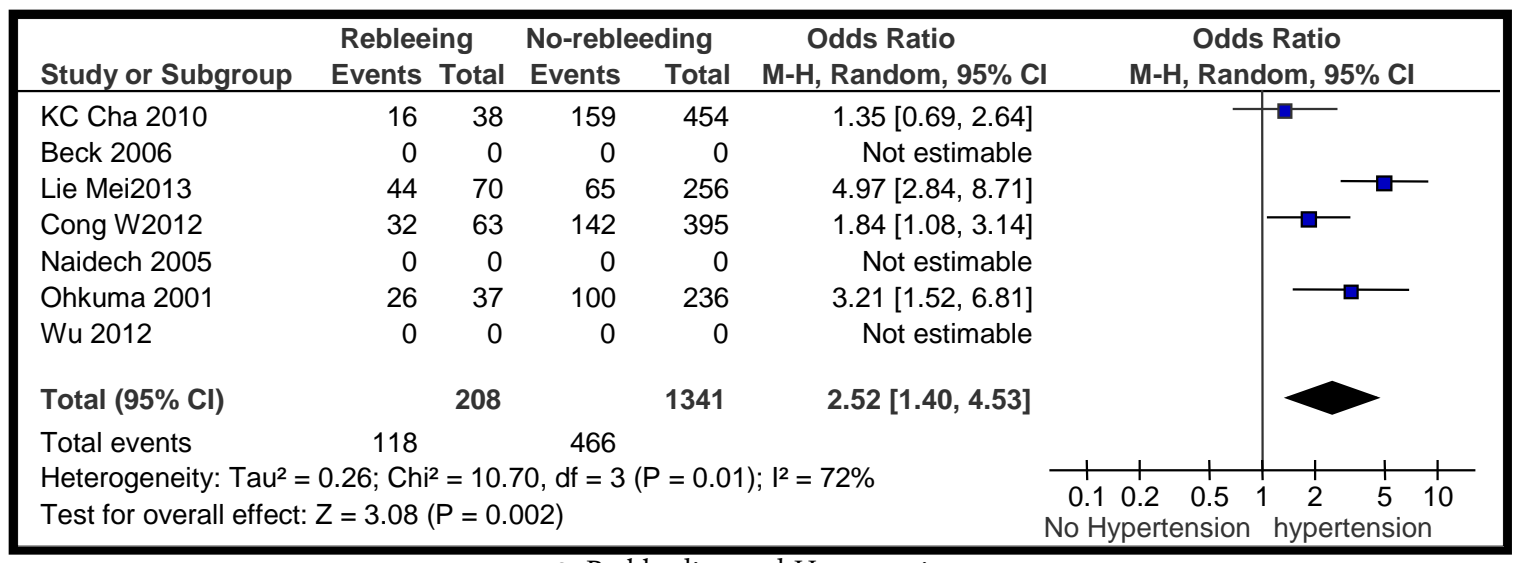

3. Re-bleeding and Hypertension:

There are 4 studies describing hypertension and re-bleeding. Pooled effects: OR (95\% CI): 2.52 (1.40, 4.53), P-values for pooled effect: $0.002, \mathrm{P}<0.05$, there is significant statistical difference between the subgroups.

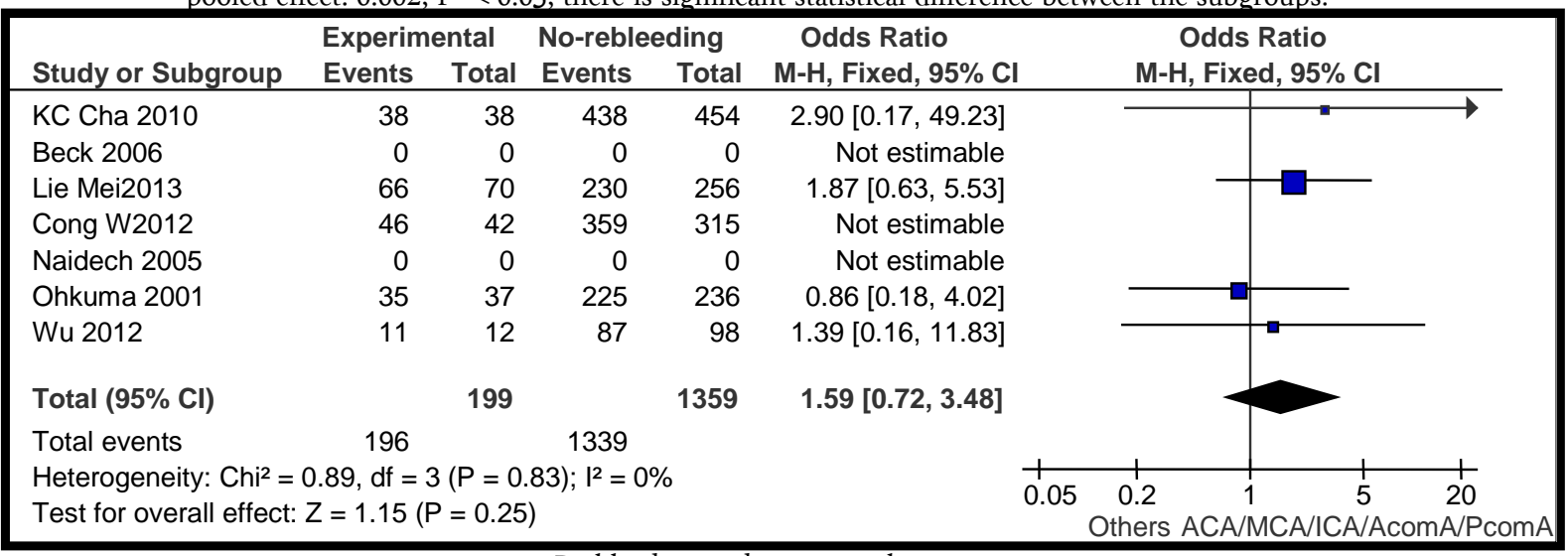

4. Re-bleeding and aneurysm location:

There are 5 studies describing aneurysm location and re-bleeding. Pooled effects: OR (95\% CI): 1.59 (0.72-3.48), P-values for pooled effect: $0.25, \mathrm{P}>0.05$, there is no significant statistical difference between the subgroups.

\begin{tabular}{|c|c|c|c|c|c|c|}
\hline Study or Subgroup & \multicolumn{2}{|c|}{ Experimental } & \multicolumn{2}{|c|}{ No-rebleeding } & $\begin{array}{l}\text { Odds Ratio } \\
\text { M-H, Fixed, } 95 \% \mathrm{Cl}\end{array}$ & $\begin{array}{c}\text { Odds Ratio } \\
\text { M-H, Fixed, } 95 \% \mathrm{Cl}\end{array}$ \\
\hline KC Cha 2010 & 1 & 38 & 38 & 454 & $0.30[0.04,2.22]$ & -2 \\
\hline Beck 2006 & 0 & 0 & 0 & 0 & Not estimable & \\
\hline Lie Mei2013 & 0 & 0 & 0 & 0 & Not estimable & \\
\hline Cong W2012 & 12 & 54 & 60 & 375 & $1.50[0.75,3.02]$ & \\
\hline Naidech 2005 & 0 & 0 & 0 & 0 & Not estimable & \\
\hline Ohkuma 2001 & 0 & 0 & 0 & 0 & Not estimable & \\
\hline Wu 2012 & 0 & 0 & 0 & 0 & Not estimable & \\
\hline Total (95\% Cl) & & 92 & & 829 & $1.11[0.58,2.09]$ & \\
\hline Total events & 13 & & 98 & & & \\
\hline $\begin{array}{l}\text { Heterogeneity: } \mathrm{Chi}^{2}= \\
\text { Test for overall effect: }\end{array}$ & $\begin{array}{l}2.38, \mathrm{df}= \\
\mathrm{Z}=0.31\end{array}$ & $\begin{array}{l}(P=0 \\
=0.76\end{array}$ & $12) ; I^{2}=$ & & & \begin{tabular}{|cccc}
0.02 & 0.1 & 1 & 10 \\
vours & [experimental] & Favours [control] \\
\end{tabular} \\
\hline
\end{tabular}

5. Re-bleeding and multiple aneurysms:

There are 5 studies describing multi aneurysm and re-bleeding. Pooled effects: OR (95\% CI): 1.11 (0.58, 2.09), P-values for pooled effect: $0.76, \mathrm{P}>0.05$, there is no significant statistical difference between the subgroups. 
DOI: 10.2478/romneu-2014-0014

\begin{tabular}{|c|c|c|c|c|c|c|c|c|}
\hline \multirow[b]{2}{*}{ Study or Subgroup } & \multicolumn{2}{|c|}{ Experimental } & \multicolumn{2}{|c|}{ No-rebleeding } & \multirow{2}{*}{$\begin{array}{c}\text { Odds Ratio } \\
\text { M-H, Random, } 95 \% \mathrm{Cl}\end{array}$} & \multirow{2}{*}{\multicolumn{2}{|c|}{$\begin{array}{c}\text { Odds Ratio } \\
\text { M-H, Random, } 95 \% \mathrm{Cl}\end{array}$}} & \\
\hline & Events & Total & Events & Total & & & & \\
\hline KC Cha 2010 & 10 & 38 & 96 & 451 & $1.32[0.62,2.81]$ & & a & \\
\hline Beck 2006 & 13 & 23 & 55 & 214 & $3.76[1.56,9.06]$ & & & \\
\hline Lie Mei2013 & 52 & 70 & 105 & 256 & $4.15[2.30,7.50]$ & & & \\
\hline Cong W2012 & 0 & 0 & 0 & 0 & Not estimable & & & \\
\hline Naidech 2005 & 0 & 0 & 0 & 0 & Not estimable & & & \\
\hline Ohkuma 2001 & 0 & 0 & 0 & 0 & Not estimable & & & \\
\hline Wu 2012 & 7 & 12 & 27 & 98 & $3.68[1.08,12.60]$ & & & \\
\hline Total $(95 \% \mathrm{Cl})$ & & 143 & & 1019 & $2.91[1.62,5.22]$ & & & \\
\hline Total events & 82 & & 283 & & & & & \\
\hline \multicolumn{6}{|c|}{ Heterogeneity: $\mathrm{Tau}^{2}=0.17 ; \mathrm{Chi}^{2}=6.04, \mathrm{df}=3(\mathrm{P}=0.11) ; \mathrm{I}^{2}=50 \%$} & $\begin{array}{ll}0.05 & 0.2 \\
\text { size small }(<10)\end{array}$ & $\begin{array}{lr}1 & 5 \\
\text { size large }\end{array}$ & 20 \\
\hline
\end{tabular}

\section{Re-bleeding and size:}

There are 4 studies describing aneurysm size and re-bleeding. Pooled effects: OR (95\% CI): 2.91 (1.62, 5.22), P-values for pooled effect: $0.0003, \mathrm{P}<0.05$, there is significant statistical difference between the subgroups.

\begin{tabular}{|c|c|c|c|c|c|c|c|}
\hline Study or Subgroup & \multicolumn{2}{|c|}{ Rebleeding } & \multicolumn{2}{|c|}{ No-rebleeding } & $\begin{array}{c}\text { Odds Ratio } \\
\text { M-H, Random, } 95 \% \mathrm{Cl}\end{array}$ & \multicolumn{2}{|c|}{$\begin{array}{c}\text { Odds Ratio } \\
\text { M-H, Random, } 95 \% \mathrm{Cl}\end{array}$} \\
\hline KC Cha 2010 & 33 & 38 & 123 & 454 & $17.76[6.78,46.53]$ & & $\longrightarrow$ \\
\hline Beck 2006 & 0 & 0 & 0 & 0 & Not estimable & & \\
\hline Lie Mei2013 & 31 & 70 & 65 & 256 & $2.34[1.35,4.05]$ & & \\
\hline Cong W2012 & 12 & 63 & 46 & 395 & $1.79[0.89,3.59]$ & & \\
\hline Naidech 2005 & 26 & 40 & 133 & 532 & $5.57[2.83,10.98]$ & & \\
\hline Ohkuma 2001 & 24 & 37 & 40 & 236 & $9.05[4.25,19.26]$ & & \\
\hline Wu 2012 & 0 & 0 & 0 & 0 & Not estimable & & \\
\hline Total $(95 \% \mathrm{Cl})$ & & 248 & & 1873 & $4.94[2.29,10.68]$ & & \\
\hline Total events & 126 & & 407 & & & & \\
\hline \multicolumn{6}{|c|}{$\begin{array}{l}\text { Heterogeneity: } \mathrm{Tau}^{2}=0.63 ; \mathrm{Chi}^{2}=23.51, \mathrm{df}=4(P=0.0001) ; \mathrm{I}^{2}=83 \% \\
\text { Test for overall effect: } Z=4.07(\mathrm{P}<0.0001)\end{array}$} & $\begin{array}{c}0.05 \quad 0.2 \\
\text { Score }<=|1|\end{array}$ & $\begin{array}{cc}5 & 20 \\
\text { Score }>\text { III } & \\
\end{array}$ \\
\hline
\end{tabular}

\section{Re-bleeding and Hunt \& Hess:}

There are 5 studies describing Hunt \& Hess and re-bleeding. Pooled effects: OR (95\% CI): 4.94 (2.29, 10.68), P-values for pooled effect: $0.0001, \mathrm{P}<0.05$, there is significant statistical difference between the subgroups.

\begin{tabular}{|c|c|c|c|c|c|c|c|}
\hline Study or Subgroup & \multicolumn{2}{|c|}{ Rebleeding } & \multicolumn{2}{|c|}{ No-rebleeding } & $\begin{array}{c}\text { Odds Ratio } \\
\text { M-H, Fixed, 95\% Cl }\end{array}$ & \multicolumn{2}{|c|}{$\begin{array}{c}\text { Odds Ratio } \\
\text { M-H, Fixed, 95\% Cl }\end{array}$} \\
\hline KC Cha 2010 & 36 & 38 & 329 & 454 & $6.84[1.62,28.83]$ & & - \\
\hline Beck 2006 & 20 & 23 & 160 & 211 & $2.13[0.61,7.44]$ & & \\
\hline Lie Mei2013 & 47 & 70 & 140 & 256 & $1.69[0.97,2.95]$ & & \\
\hline Cong W2012 & 0 & 0 & 0 & 0 & Not estimable & & \\
\hline Naidech 2005 & 0 & 0 & 0 & 0 & Not estimable & & \\
\hline Ohkuma 2001 & 0 & 0 & 0 & 0 & Not estimable & & \\
\hline Wu 2012 & 11 & 12 & 80 & 98 & $2.48[0.30,20.41]$ & & \\
\hline Total $(95 \% \mathrm{Cl})$ & & 143 & & 1019 & $2.29[1.45,3.61]$ & & \\
\hline Total events & 114 & & 709 & & & & \\
\hline $\begin{array}{l}\text { Heterogeneity: } \mathrm{Chi}^{2}= \\
\text { Test for overall effect: }\end{array}$ & $\begin{array}{l}3.37, d f= \\
Z=3.55\end{array}$ & $\begin{array}{l}3(P= \\
P=0.0\end{array}$ & $\begin{array}{l}0.34) ; 1^{2}= \\
004)\end{array}$ & & & $\begin{array}{l}0.020 .1 \\
\text { Fisher grade }<3\end{array}$ & $1 \underset{10}{10} 50$ \\
\hline
\end{tabular}

8. Re-bleeding and Fisher Grade:

There are 4 studies describing Fisher Grade and re-bleeding. Pooled effects: OR (95\% CI): 2.29 (1.45, 3.61), P-values for pooled effect: $0.0004, \mathrm{P}<0.05$, there is significant statistical difference between the subgroups. 


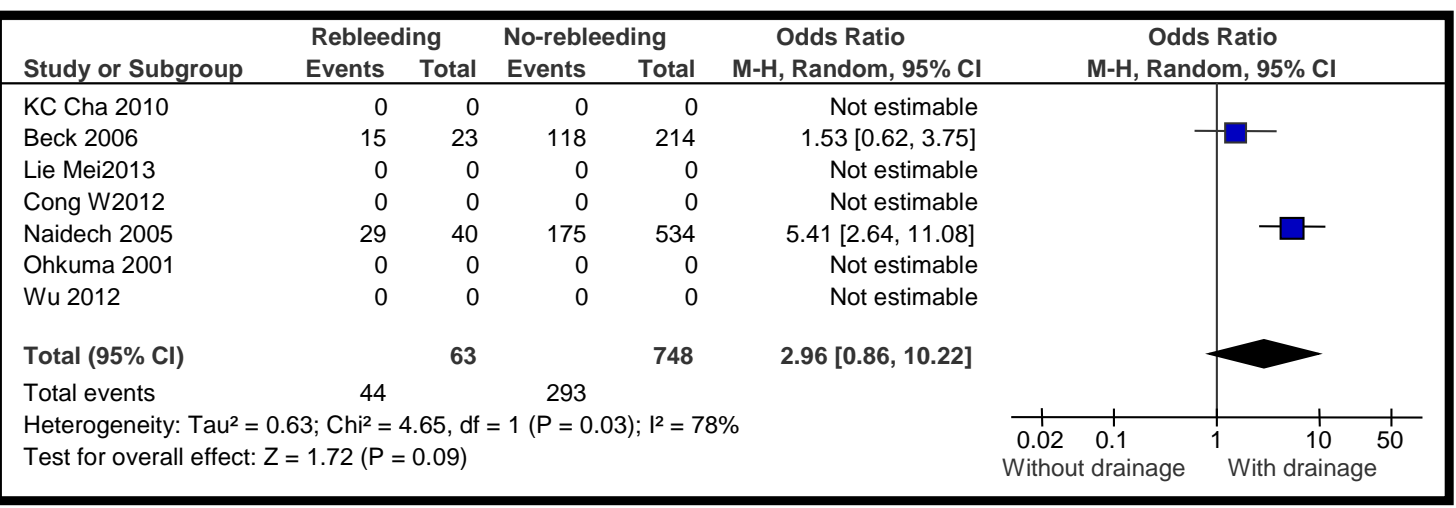

9. Re-bleeding and EVD:

There are 2 studies describing EVD and re-bleeding. Pooled effects: OR (95\% CI): 2.96 (0.86-10.22), P-values for pooled effect: $0.09, \mathrm{P}>0.05$, there is no significant statistical difference between the subgroups.

\section{Discussion}

$10-15 \%$ of patients with aneurysmal $\mathrm{SAH}$ die before reaching medical care [1]. A further 5\% die within the first 24 hours of SAH. By the 30th day of SAH, the overall case fatality rate increases to nearly $50 \%[1,2]$. Of the survivors $25-30 \%$ of patients re-bleed within the first four weeks from the SAH, of these; approximately $70 \%$ die after the re-bleed [5]. After the first six weeks of SAH, the re-bleeding rate is about $4 \%$ per year. $50 \sim 90 \%$ of re-bleeding episodes occur in the first 6 hours after the primary bleed [3] [4]. The re-bleeding rate in this Meta analysis between: $7.5 \% \sim 27.3 \%$. The weighted average rate of re-bleeding is $11.3 \%$ with $95 \%$ confidence interval [CI]: $(10.1,12.6) \%$.

\section{1-Age and sex:}

Advanced age people has poor outcome after SAH [12]. Several studies have reported that old people has higher tendency to re-bleed than the control cases [12]. Naidech et al. and Cong W. et al. suggested that age was not associated with re-bleeding [13] [14]. In our study we did not find significant difference between rebleeding and non re-bleeding groups.

Our analysis showed that re-bleeding risk for males was significantly higher than for females. This finding was quite different from other reports claim that female patients are high risk factor [15].

\section{2-Hunt \&Hess Grade:}

The patient's clinical and neurological condition on admission was evaluated by famous Hunt and Hess grade system [16]. Several studies reported that poor Hunt and Hess grade was significantly relate to aneurysmal re-bleeding [4] [5] [13] [17] [18 ] [19]. Our result does not differ from these studies. One study by Inagawa et al. could not find relation between poor Hunt and Hess and re-bleeding [20]. This may due poor condition patients were frequently intubated, sedated, and therefore difficult to diagnosis clinically.

\section{3-High SBP:}

Naidech et al found that hypertension is 
DOI: 10.2478/romneu-2014-0014

not associated with re-bleeding after subarachnoid hemorrhage. In a large study reported that the re-bleeding rate is $6.9 \%$ after admission to the hospital, but did not find relationship to blood pressure [21]. Many other studies found that high blood pressure after the initial SAH can lead to the risk of re-bleeding [4] [17] [22]] [23]. Ohkuma found that re-bleeding is more common in patients with high systolic blood pressure more than $160 \mathrm{mmHg}$ [4].

Our analysis shows high systolic blood pressure is a major risk for re-bleed in SAH patients.

\section{4-Fisher Grade:}

The amounts of clot in the subarachnoid space demonstrated on initial CT scan. Patients with intracerebral or intraventricular hematoma usually present with poor clinical condition (high $\mathrm{H} \& \mathrm{H}$ grade) and high blood pressure on admission. This may be can lead to early re-rupture of aneurysm. Reynold et al. reported higher incidence of intracerebral hematoma in patients with signs of repeated aneurysm rupture [24]. The high incidence of this bleeding pattern may substantially contribute to poor clinical condition of patient with repeat SAH. Inagawa et al and Lie -Mei Guo et al did not find any correlation between Fisher Grade and re-bleeding [23] [20]. This is differ from our study which shows Fisher Grade is a risk factor for re-bleeding.

\section{5-External ventricular drainage (EVD):}

Acute hydrocephalus is a common complication after aneurysmal SAH, needs emergent cerebral spinal fluid (CSF) drainage. Often results in improvement in patient clinical condition. There are many conflicting studies that assumed CSF drainage can lead to re-bleeding [13] [25] [26]. The most accepted theory is that, CSF drainage in patients with unsecured, recently rupture aneurysm may increase the transmural pressure across the aneurysm wall, and this may lead to increasing likelihood of re-bleeding [27].

Beck et al did not find strong correlation between external ventricular drainage and re-bleeding [28]. In this analysis we did not find that EVD a risk factor for re-bleeding in aneurysmal $\mathrm{SAH}$ patients.

\section{6-Aneurysm Location:}

Previous studies showed the location of the aneurysm was implicated in aneurysmal re-bleeding [3] [28], especially in the anterior communicating artery (AComA), and posterior communicating artery (PComA) [29]. Cong W. et al study showed posterior circulation aneurysm patient is in higher bleeding risk than those in the non-posterior circulation [14].

The present study revealed that the aneurysm location was not a risk factor for re-bleeding. This result agrees with previous studies by Lei-Mei Guo and $\mathrm{Wu}$ et al [23] [30].

\section{7-Aneurysm Size:}

Most of studies emphasize that aneurysm size is a major risk for initial rupture [31] [32]. Lei-Mei Guo et al found that the probability of re-bleeding in 
patients with aneurysms larger than 10 $\mathrm{mm}$ was 1.624 fold greater than those with aneurysms of $10 \mathrm{~mm}$ or less [23], but this result is not consistent with other studies [22] [17].

In this analysis we found that aneurysm size has a significant risk on re-bleeding.

\section{8-Multiple Aneurysm:}

Patients with several aneurysm have more fragile vessels wall, that's may prone to form multiple aneurysms or prone to rebleeding after the aneurysm has already ruptured. Some studies showed there was no significant difference between rebleeding and non re-bleeding in patients who harboring multiple aneurysms [14]. But Beck et al. reported multiple aneurysms patients have a risk of rebleeding [28]. In our analysis we did not find any correlation between multiple aneurysms and re-bleeding.

\section{Conclusion}

Sex, Hypertension, Hunt and Hess grade, aneurysm size, and Fisher Grade are major risk for re-bleeding in aneurysmal Subarachnoid Hemorrhage patients. We did not find any correlation between age, EVD, aneurysm location and multiple aneurysms and aneurysm re-bleeding. We advocate early surgery for primary ruptured aneurysm in good clinical condition patients to eliminate the risk of re-bleeding. Maintained systemic blood pressure in a moderate hypertensive range (140 to $160 \mathrm{mmHg}$ ) also can prevent early re-rupture of the aneurysm.

\section{Limitation of this study}

All the studies are retrospective, the data quality could not be monitored. Only few studies described inclusion and exclusion criteria, each study has different study objective, and diagnostic criteria could be different from hospital to hospital. Risk factors studied vary from study to study, with different focus.

\section{Correspondence address \\ Alfotih Gobran Taha \\ Sun Yat Sen Memorial Hospital, Neurosurgery \\ Department, Sun Yat Sen Medical University \\ P. O. BOX 510120, GuangZhou, GuangDong \\ Province, People's Republic of China \\ Tel: 008613066381670 \\ Email:gta_alfotih@yahoo.com}

\section{References}

1. Pobereskin LH. Incidence and outcome of subarachnoid haemorrhage: a retrospective population based study. J Neurol Neurosurg Psychiatry. 2001; 70: 340-343.

2. Hop JW, Rinkel GJ, Algra A, et al. Case-fatality rates and functional outcome after subarachnoid haemorrhage: a systematic review. Stroke.1997; 28: 660664.

3. Tanno Y, Homma M, Oinuma M, et al.Rebleeding from ruptured intracranial aneurysms in North Eastern Province of Japan: a cooperative study. J Neurol Sci.2007; 258: 11-16.

4. Ohkuma H, Tsurutani H, Suzuki S.Incidence and significance of early aneurysmal rebleeding before neurosurgical or neurological management. Stroke. 2001; 32: 1176-1180.

5. Rosenorn J, Eskesen V, Schmidt K, et al. The risk of rebleeding from ruptured intracranial aneurysms. J Neurosurg. 1987; 67: 329-332.

6. Ameen AA, Illingworth R.Anti-fibrinolytic treatment in the preoperative management of subarachnoid haemorrhage caused by ruptured intracranial aneurysm. J Neurol Neurosurg Psychiatry.1981; 44: 220-6.

7. Kassell N, Torner J, Haley C Jr, et al. The International Cooperative Study on the Timing of 
Aneurysm Surgery Part 1: overall management results. J Neurosurg.1990; 73: 18-36.

8. Kassell N, Torner J, Jane J, et al. The International Cooperative Study on the Timing of Aneurysm Surgery. Part 2: surgical results. J Neurosurg.1990; 73: 37-47.

9. SolenskiN J, Haley EC, Kassell NF, et al. Medical complications of aneurysmal subarachnoid hemorrhage: A report of the multicenter, cooperative aneurysm study. Participants of the multicenter cooperative aneurysm study. Crit Care Med.1995; 23: 1007-17.

10.Biller J, Toffol G J, Kassell N F, et al. Spontaneous subarachnoid hemorrhage in young adults. Neurosurgery. 1987; 21: 664-7.

11.Sakaki T, Morimoto T, Hoshida T, et al.Rebleeding during transport of patients with a ruptured intracranial aneurysm. J Stroke Cerebrovasc Dis. 1999; 8: 38-41.

12.Lanzino G, Kassell NF, Germanson TP, et al. Age and outcome after aneurysmal subarachnoid hemorrhage: why do older patients fare worse? J Neurosurg. 1996; 85: 410-418.

13. Naidech AM, Janjua N, Kreiter KT, et al. Predictors and impact of aneurysm rebleeding after subarachnoid hemorrhage. Arch Neurol. 2005; 62: 410-6.

14. Cong W, Zhongxin Z, Tiangui L, et al. Risk factors for rebleeding of aneurysmal subarachnoid hemorrhage based on the analysis of on-admission information. Turk Neurosurg.2012; 22 (6): 675-81.

15.Jamous MA, Nagahiro S, Kitazato KT, Tamura T, et al. Role of estrogen deficiency in the formation and progression of cerebral aneurysms. Part II: Experimental study of the effects of hormone replacement therapy in rats. J Neurosurg 2005; 103: 1052-1057.

16. Hunt WE, Hess RM. Surgical risk as related to time of intervention in the repair of intracranial aneurysms. J Neurosurg.1968; 28 (1): 14-20

17. Fujii Y, Takeuchi S, Sasaki O, Minakawa T, Koike $\mathrm{T}$, Tanaka R. Ultra-early rebleeding in spontaneous subarachnoid hemorrhage. J Neurosurg.1996; 84: 35-42. 18. Hijdra A, Vermeulen M, van Gijn J, et al. Rerupture of intracranial aneurysms: A clinicoanatomic study. J Neurosurg. 1987; 67: 29-33.

19. Roganovic Z, Pavlicevic G, Tadic R, et al. Risk factors for the onset of vasospasm and rebleeding after spontaneous subarachnoid hemorrhage. Vojnosanit Pregl. 2001; 58: 17-23 [in Serbian].

20. Inagawa $T$, Kamiya $K$, Ogasawara $H$, et al. Rebleeding of ruptured intracranial aneurysms in the acute stage. Surg Neurol. 1987; 28: 93-99.
21.Kitsuta Y, Suzuki N, Sugiyama M, et al.Changes in level of consciousness and association with hyperglycemia as tool for predicting and preventing rebleeding after spontaneous subarachnoid hemorrhage. Prehosp Disaster Med.2006; 21: 190-195.

22. Cha KC, Kim JH, Kang HI, et al. Aneurysmal rebleeding: factors associated with clinical outcome in the rebleeding patients. J Korean Neurosurg Soc. 2010; 47: 119-23.

23. Guo LM, Zhou HY, Xu JW, et al. Risk factors related to aneurysmal rebleeding. World Neurosurgery.2013; 76: 292-298.

24. Reynolds A, Shaw CM. Bleeding Patterns from ruptured intracranial aneurysms: an autopsy series of 205 patients. Surg Neurol.1980; 15: 232-5.

25. Mehta V, Holness RO, Connolly K, Walling S, Hall R. Acute hydrocephalus following aneurysmal subarachnoid hemorrhage. Can J Neurol Sci. 1996; 23: 40-45.

26. Rajshekhar V, Harbaugh RE. Results of ventriculostomy with external ventricular drainage for acute hydrocephalus following subarachnoid hemorrhage. Acta Neurochir (Wien). 1992; 115: 8-14. 27. Paré L, Delfino R, Leblanc R. The relationship of ventricular drainage to aneurysmal rebleeding. J Neurosurg.1992; 76: 422-427.

28. Beck J, Raabe A, Szelenyi A, et al. Sentinel headache and the risk of rebleeding after aneurysmal subarachnoid hemorrhage. Stroke.2006; 37: 2733-7.

29. Nibbelink DW, Torner JC, Henderson WG.Intracranial aneurysms and subarachnoid hemorrhage. A cooperative study. Antifibrinolytic therapy in recent onset subarachnoid hemorrhage. Stroke.1975; 6: 622-629.

30. Wu TC, Tsui YK, Chen TY, et al. Rebleeding of aneurysmal subarachnoid hemorrhage in computed tomography angiography: risk factor, rebleeding pattern, and outcome analysis. J Comput Assist Tomogr. 2012; 36 (1): 103-8.

31. Prestigiacomo CJ, $\mathrm{He} \mathrm{W}$, Catrambone J, et al. Predicting aneurysm rupture probabilities through the application of a computed tomography angiographyderived binary logistic regression model. J Neurosurg.2009; 110: 1-6.

32. Salary M, Quigley MR, Wilberger JE Jr. Relation among aneurysm size, amount of subarachnoid blood, and clinical outcome. J Neurosurg.2007; 107: 13-17. 